\title{
The Relationship Between Functional Constipation and Emotional, Social, Physical, and Educational Functioning of Children
}

\author{
Hasan Karami, ${ }^{1}$ Jamshid Yazdani, ${ }^{2,3}$ Najmeh Khalili, ${ }^{4}$ and Mehdi Pourasghar ${ }^{2,5,6,}$ \\ ${ }^{1}$ Department of Pediatrics, Mazandaran University of Medical Sciences, Sari, Iran \\ ${ }^{2}$ Psychiatry and Behavioral Sciences Research Center, Addiction Institute, Mazandaran University of Medical Sciences, Sari, Iran \\ ${ }^{3}$ Department of Health Sciences, Faculty of Health, Mazandaran University of Medical Sciences, Sari, IR Iran \\ ${ }^{4}$ Mazandaran University of Medical Sciences, Sari, Iran \\ ${ }^{5}$ Department of Psychiatry, Mazandaran University of Medical Sciences, Sari, Iran \\ ${ }^{6}$ Department of Psychotherapy, Rozbeh Hospital, Tehran University of Medical Sciences, Tehran, Iran \\ "Corresponding author: Mehdi Pourasghar, Psychiatry and Behavioral Sciences Research Center, Addiction Institute, Zare Hospital, Neka Road, Sari, Mazandaran, Iran. Tel/Fax: \\ +98-1133258109, E-mail: me_pourasghar@yahoo.com
}

Received 2016 May 14; Revised 2017 January 11; Accepted 2017 February 07.

\begin{abstract}
Background: Functional constipation is common in children and may cause many behavioral and psychological problems that could ultimately affect the quality of life.

Objectives: The present study aimed at comparing the functional constipation and emotional, social, physical, and educational functioning of children with chronic constipation and healthy individuals, and also distinguishing the level of awareness about quality of life in children and their parents.

Materials and Method: This was a case control study. The study population included 208 children (12.4 years) and their parents who visited the children's gastroenterology clinic of Boo-Ali Sina hospital. Using available sampling, 104 children with chronic functional constipation problems and their parents were selected as the sample and compared with a control group $(n=104)$ for quality of life satisfaction. Quality of Life Questionnaire was used to collect data. To analyze data, t test and analysis of variance (ANOVA) test were used with SPSS 18.

Results: The results of the data analysis revealed a statistically significant difference $(P=0.000)$ between the quality of life in patients and the control group. Parents of patients with chronic constipation also reported lower quality of life in their children.

Conclusions: According to the results of the present study, there was a correlation between the quality of life and constipation; and a decrease in quality of life was observed in children with this disorder. Therefore, psychological evaluation and treatment strategies may be effective in improving the functional constipation and quality of life.
\end{abstract}

Keywords: Children, Constipation, Quality of Life

\section{Background}

Constipation with or without incontinence is a common disorder in children, affecting $3 \%$ to $5 \%$ of children who have been visited by a pediatrician; and at the community level, this frequency have been reported to be $28 \%$ (1-3). Moreover, $25 \%$ to $30 \%$ of patients who visit children's gastroenterology clinic also suffer from this condition. In most cases of constipation in children, no medical cause has been found, and they are mostly classified as having idiopathic or functional constipation $(4,5)$. Constipation is a symptom and is not considered a disease, thus, many differential diagnoses should be considered. Behavioral and psychological problems are associated with chronic constipation, which involves a range of disorders as well. In his study, Van Everdingen (6) found that 95\% of children with fecal incontinence (with or without constipation) had psychiatric problems. However, psychological disorders are often not well known and thus not examined. Neglecting psychological causes may be due to the lack of understanding the relationship between constipation and psychological problems. Moreover, in constipation and psychological problems, it is difficult to differentiate which one is primary and which is secondary (4-7).

The chronic course of illness and maladaptive family functioning may cause many behavioral problems in children, which may affect their usual activities. Problems associated with or due to constipation include loss of confidence, loss or deterioration of coping skills, school refusal, and mood disorders $(1,5,8,9)$.

Enjoying a good quality of life has always been our desire. First, quality of life was evaluated by improving the appearances such as income, education, health, and housing, because having only more material wellbeing indicated a better quality of life $(10,11)$. Gradually, psychologists and health professionals proposed that the main criterion for having a good quality of life is not only having the resources and wealth, but it depends more on the sat- 
isfaction and mental perception of the concept of work, employment, and housing (12). Further investigation revealed that one of the issues that could affect quality of life is chronic diseases. Arnold Wald (11) also evaluated all relevant articles about the pediatric quality of life (QOL). Evaluation of the quality of life of children and adults with chronic constipation showed that numerous studies have emphasized the significant functional and successful treatment of constipation in adults and its impact on the quality of life. However, there are no sufficient data on the treatment of constipation in children and its effect on their quality of life. On the other hand, Ozakutan (13), using child behavior checklist (CBCL) and Symptom Checklist-90 (SCL-90), found no behavioral problems in children with constipation and their parents compared to the control group.

Quality of life is highly important for humans. However, the relationship between quality of life and functional chronic constipation is not clear, and lack of any research on this area in Mazandaran province encouraged us to conduct this research to better understand chronic constipation.

\section{Objectives}

Because psychological studies on the causes of constipation in children have been very limited in Mazandaran province, in this study, we aimed at evaluating the quality of life of children with functional chronic constipation in a referral pediatric hospital (Boo-Ali Sina) of Mazandaran province and estimating the level of awareness about quality of life in children and their parents.

\section{Materials and Methods}

This was a case control study with available sampling method, in which 104 children who referred to Boo-Ali Sina hospital in city of Sari from across the province, and who were diagnosed with functional constipation by a pediatric gastroenterologist (by considering the history, physical examinations, and paraclinical investigations) participated. In this study, 104 children were selected for the control group form the children of close relatives of the patients or clients of the center who had no organic neurologic diseases in diagnostic evaluations by a pediatric gastroenterologist. After providing explanations to the participants to complete the questionnaire, we distributed the questionnaires among children and their parents.

\subsection{Inclusion Criteria}

Children 4 to 12 years old
Having $\geq 2$ following symptoms for more than 2 months:

-Defecation $\leq 2$ times a week

-Incontinence $\geq$ once a week

-Avoiding defecation (with holding)

-History of painful defecation

-Fecal impactions in the rectum

\subsection{Exclusion Criteria}

-Detecting any organic cause at the beginning or during the treatment of patients by the pediatric gastroenterologist

-Patients with other chronic diseases, internal or acute and chronic or acute neurological diseases based on the recorded or obtained history by the pediatric gastroenterologist from the parents and those with mental retardation were excluded from the study.

-The willingness of families to withdraw from the project

\subsection{Population, Sampling Methods and the Sample}

The study population included children and their parents who referred to children's gastroenterology clinic of Boo-Ali Sina hospital in the city of Sari and who were visited by a pediatric gastroenterologist. A total of 208 children ( $4-12$ years) and their parents participated in the present study. Using available sampling, 104 children with chronic functional constipation problems and their parents were selected and compared with the 104 individuals of the control group for the quality of life satisfaction. Sampling was done using nonprobability and cconvenience sampling method was used based on the purpose of the study (13). The sample size based on the average score of depression and anxiety in both groups was determined with $95 \%$ confidence and power of $80 \%$ as follows:

$$
\begin{aligned}
& \mathrm{N}=(1 / 96+0 / 84)(5 / 462+5 / 712)=55 \\
& 2(7-10)
\end{aligned}
$$

\subsection{Data Collection Tools}

\subsubsection{Pediatric Quality of Life Questionnaire (Peds QOL)}

The standard form of the questionnaire comes with 4 sections of children's physical activity, emotional functioning, communication, and activities in school. Physical activity includes 8 questions and the rest of the sections have 5 standard questions. A total of 23 questions have been answered. The questions had 5 answers of never (zero), almost never (score 1), sometimes (score 2), often (score 3), and almost always (score 4), and they have been scored in a reverse manner, meaning zero scores 100 points, 1 scores 75 points, 2 scores 50, 3 scores 25 , and 4 scores zero. The 
questionnaire has been set for parents and children separately, so the parents of all children in both groups filled out their own questionnaire. For children younger than 8 years, questions were read by the interviewer and children over 8 years have answered the questions independently. The validity of the questionnaire has been determined by Mohammedian et al. for the Persian population and showed content validity of 0.84 for PedsQOL. The correlation coefficient between the PedsQOL and its 4 subscales was acceptable $(r>0.7)$. The PedsQOL had a good internal consistency $(\alpha=0.82)$. Cronbach alpha coefficients of different categories of the tool ranged from 0.65 to 0.77 . There was a significant relationship between PedsQL of children and parents (14).

\subsection{Statistical Analysis}

For descriptive analysis of data, statistical indicators like mean and standard deviation (SD) were used, and analysis of variance (ANOVA) was used to assess the groups.

\section{Results}

In the present study, 104 children with an average age of $7.21 \pm 2.52$ years in the case group and 104 children with an average age of $8.85 \pm 2.32$ years in the control group were studied. Children were placed into 2 groups of $104 \mathrm{pa}-$ tients with constipation and 104 healthy children with no disease. Children and parents in case and control groups answered the QOL questionnaires. There were 53 females and 51 males in the case group, and 67 females and 37 males in the controls group (Figure 1).

In questionnaires completed by the children, quality of life has been significantly lower in children with constipation in the emotional, social, physical function, and performance in school compared with the control group (Table 1).

Similar results have been obtained in the questionnaires completed by the parents (Table 2 ).

The average of the quality of life was statistically significant difference among patients $(\mathrm{P}=0.000)$ compared to the controls in the questionnaire (QOL Child Report); and the mean of the quality of life in the case group was $54.04 \pm$ 17.79 , and it was $83.99 \pm 11.09$ in the control group. Quality of life in the parents' questionnaires (QOL Parent Report) was significantly different in both groups $(P=0.000)$; and the mean of quality of life in the case and control groups was $49.72 \pm 16.46$ and $79.94 \pm 12.84$, respectively.

The results of the questionnaire revealed that the quality of life of parents and children with constipation was similar in males and females, and there were no significant differences in the quality of life of males and females ( $P$ $>0.05$ ) (Figure 2).

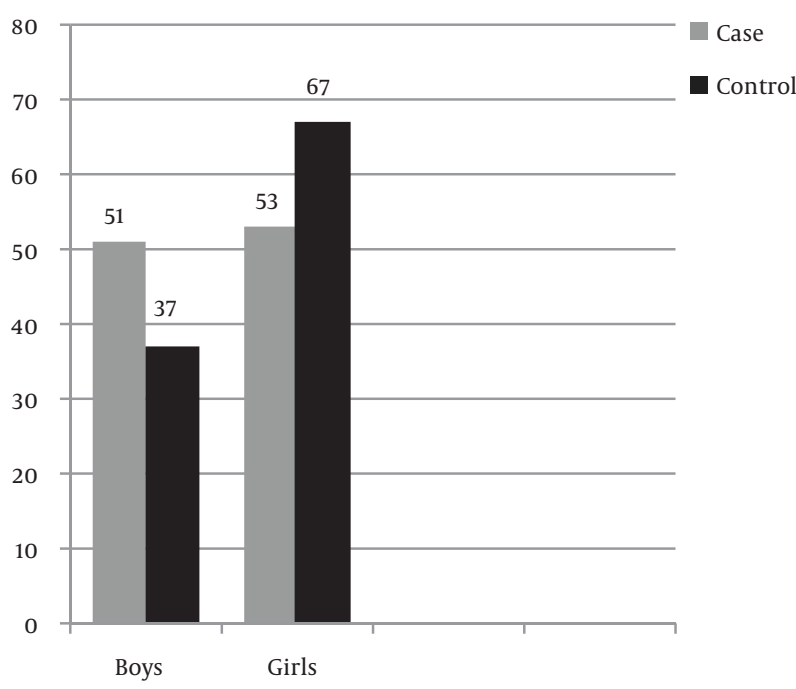

Figure 1. Comparison of Sex Distribution of Functional Constipation Group and Healthy Controls

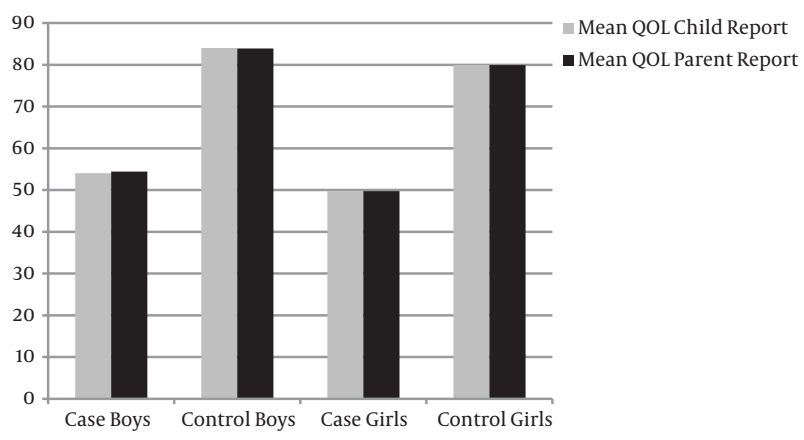

Figure 2. Comparing the Quality of Life in Functional Constipation Group and Healthy Controls in Each Sex

The average quality of life in the questionnaire for parents was lower than the average quality of life questionnaire for children, and it was statistically significant $(\mathrm{P}=$ 0.000) (Figure 3).

\section{Discussion}

Quality of life is an important index of any population. In the present study, children who suffered from functional constipation were compared with the control group using pediatric quality of life questionnaire. The results revealed that children with constipation had a significant diminished functioning in 4 areas of the questionnaire (educational, physical, social, and emotional) compared with the control group $(\mathrm{P}<0.000)$. The score of quality of life questionnaire in parents and children with constipation 
Table 1. Comparison of Quality of Life in the Treatment and Control Groups Based on Children's Questionnaires

\begin{tabular}{|c|c|c|c|c|c|c|}
\hline Variables & Group & $\mathbf{N}$ & Mean & Std. Deviation & Std. Error Mean & Sig \\
\hline \multirow{2}{*}{ Emotional functioning } & Case & 104 & 43.32 & 25.93 & 2.54 & 0.000 \\
\hline & Control & 104 & 78.53 & 18.27 & 1.79 & \\
\hline \multirow{2}{*}{ Physical functioning } & Case & 104 & 49.36 & 27.64 & 2.71 & 0.000 \\
\hline & Control & 104 & 83.47 & 11.11 & 1.09 & \\
\hline \multirow{2}{*}{ Social functioning } & Case & 104 & 47.03 & 26.64 & 2.61 & 0.000 \\
\hline & Control & 104 & 83.32 & 16.24 & 1.59 & \\
\hline \multirow{2}{*}{ Educational/school functioning } & Case & 104 & 76.46 & 16.85 & 1.65 & 0.000 \\
\hline & Control & 104 & 90.67 & 10.36 & 1.02 & \\
\hline
\end{tabular}

Table 2. Comparing the Quality of Life in the Case and Control Groups Based on the Questionnaires of Parents

\begin{tabular}{|c|c|c|c|c|c|c|}
\hline Variables & Group & $\mathbf{N}$ & Mean & Std. Deviation & Std. Error Mean & Sig \\
\hline \multirow{2}{*}{ Emotional functioning } & Case & 104 & 38.53 & 22.89 & 2.24 & 0.000 \\
\hline & Control & 104 & 76.49 & 18.25 & 1.79 & \\
\hline \multirow{2}{*}{ Physical functioning } & Case & 104 & 43.80 & 26.43 & 2.59 & 0.000 \\
\hline & Control & 104 & 79.76 & 13.68 & 1.34 & \\
\hline \multirow{2}{*}{ Social functioning } & Case & 104 & 41.45 & 26.46 & 2.39 & 0.000 \\
\hline & Control & 104 & 79.27 & 19.27 & 1.89 & \\
\hline \multirow{2}{*}{ Educational/school functioning } & Case & 104 & 75.08 & 14.88 & 1.46 & 0.000 \\
\hline & Control & 104 & 84.23 & 14.86 & 1.46 & \\
\hline
\end{tabular}

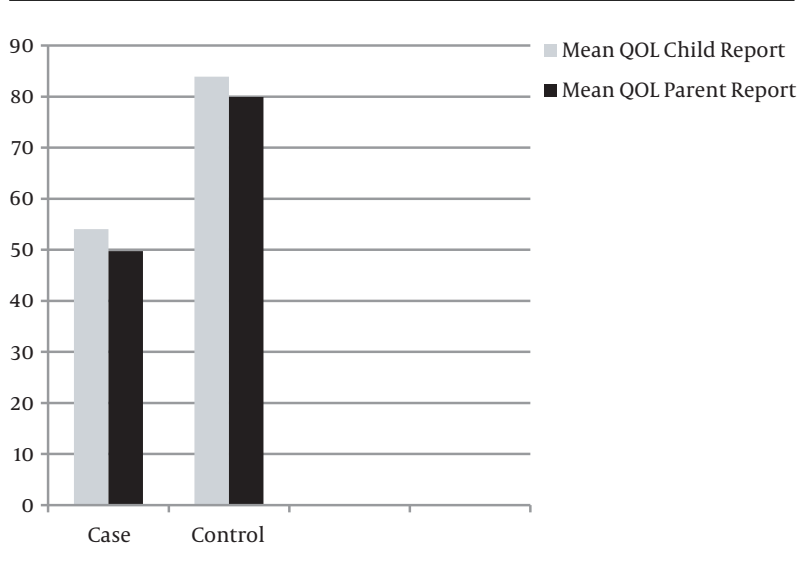

Figure 3. Comparison of the Results of Quality of Life in the Questionnaire for Parents and the One for for Children

was similar in males and females and there were no significant differences between the quality of life of males and females. These results were similar to those of the previous research $(11,12,15)$, but Ozakutan (14) found no behavioral problems in children with functional constipation and their parents compared with the control group. Perhaps, the different result of this research was because their control group had inguinal hernia and a different checklist for behavioral assessment. From the perspective of children with constipation, especially in combination with incontinence, this disease caused shame for them in the society and affected their self-esteem and made them anxious (16). On the other hand, recent studies have shown that anxiety could be one of the most important factors in reducing quality of life because anxiety reduces the functioning of an individual and affects different aspects of life of the individual and the family. Furthermore, quality of life was reduced significantly (3). In studies on patients with constipation, symptoms such as depression and anxiety were most common, and these symptoms have been more sever in children who had less family support, poor school environment, and more social problems $(2,17)$. In addition, in other studies, psychological disorders such as obsessivecompulsive and antisocial personality have been reported (5). In our study, a significant difference (children questionnaire) was found between the emotional and social performance criteria in the case and the control groups. Therefore, constipation in children can reduce their per- 
formance in the community and may decrease emotional level of these children; this finding is consistent with previous studies. Because constipation, particularly if it is accompanied by lack of appropriate waste management, causes people to worry about the risk of permanent incontinence and avoid public interactions due to the risk of sudden incontinence and being ridiculed by peers; thus, the social functioning of the patient will face a significant drop (9).

Faleiros and Machado compared the quality of life in children with constipation and without constipation. In this comparison, physical performance of children with constipation has clearly been less than the healthy people. Moreover, in the present study, children reported lower quality of life than their parents (15). Although in this study the physical performance of children with constipation was less than the control group, unlike the above study, the quality of life was reported lower by parents than by the children. In other studies, the reported quality of life was lower by parents than children, which are consistent with our study (18).

In a study conducted on patients with constipation, the results have showed that those children who attend school avoid using toilets due to their fear of toilets and this causes constipation. Therefore, the quality of academic performance also decreased in these patients (19, 20). In the current study, patients with constipation had poor educational performance compared to the control group, which could be the result of stress and fear of defecation outside the home environment. The present study revealed that family and school environment could play a key role in childhood diseases especially in constipation. According to Freud (21-23), child anal phase fixation and subsequently the failure to gain the ability to overcome this stage of development, may be harmful and reduce the child's ability to cope with anxiety and stress. Although advocates of object relation theory are convinced that the development of anxiety and subsequent problems are due to lack of proper relationship between the child and the environment, especially parents, harmful environment and lack of proper communication with the environment could have a significant share in producing neurotic symptoms including gastro-intestinal problems. Thus, such self-harm environments automatically lead to lower quality of life; and after the appearance of the symptoms, this low quality of life will be lowered even more (24).

Therefore, understanding the relationship between psych and soma and intrapsychic condition and interpersonal factors may help us perceive why chronic diseases like constipation can cause lower quality of life. According to the results of the present study, there is an association between quality of life and chronic constipation, and this disease reduces quality of life. On the other hand, presenting clinical and psychological treatment strategies for reducing the symptoms may improve the quality of life. Thus, it is recommended that in future studies the researchers focus on solutions for the treatment of patients with constipation and assess their quality of life.

\section{Acknowledgments}

The authors would like to thank all the participants for their cooperation.

\section{Footnotes}

Authors' Contribution: Hasan Karami conceived the evaluation. Hasan Karami and Najmeh Khalili did the literature review, designed the evaluation, wrote the protocol and collected the clinical data. Hasan Karami, Najmeh Khalili and Mehdi Pourasghar interpreted the clinical data. Mehdi Pourasghar drafted the manuscript. All authors read and approved the final manuscript.

Declaration of Interest: None declared.

Funding/Support: Mazandaran University of Medical Sciences supported this study.

\section{References}

1. van Everdingen-Faasen EQ, Gerritsen BJ, Mulder PG, Groeneweg M. Psychosocial co-morbidity affects treatment outcome in children with fecal incontinence. EurJPediatr. 2008;167(9) doi:10.1007/s00431007-0619-4.

2. Cox DJ, Morris JB Jr, Borowitz SM, Sutphen JL. Psychological differences between children with and without chronic encopresis. J Pediatr Psychol. 2002;27(7):585-91. doi: 10.1093/jpepsy/27.7.585. [PubMed: 12228330].

3. van Ginkel R, Reitsma JB, Buller HA, van Wijk MP, Taminiau JA, Benninga MA. Childhood constipation: longitudinal follow-up beyond puberty. Gastroenterology. 2003;125(2):357-63. doi: 10.1016/So0165085(03)00888-6. [PubMed: 12891536].

4. Staiano A, Andreotti MR, Greco L, Basile P, Auricchio S. Long-term follow-up of children with chronic idiopathic constipation. Dig Dis Sci. 1994;39(3):561-4. doi: 10.1007/BF02088343. [PubMed: 8131693].

5. Sutphen JL, Borowitz SM, Hutchison RL, Cox DJ. Long-term follow-up of medically treated childhood constipation. Clin Pediatr (Phila). 1995;34(11):576-80. doi: 10.1177/000992289503401102. [PubMed: 8565387].

6. Procter E, Loader P. A 6-year follow-up study of chronic constipation and soiling in a specialist paediatric service. Child Care Health Dev. 2003;29(2):103-9. doi:10.1046/j.1365-2214.2003.00319.x. [PubMed: 12603355].

7. Clarke MC, Chow CS, Chase JW, Gibb S, Hutson JM, Southwell BR Quality of life in children with slow transit constipation. J Pediatr Surg. 2008;43(2):320-4. doi:10.1016/j.jpedsurg.2007.10.020. [PubMed: 18280282].

8. Loening-Baucke V, Cruikshank B, Savage C. Defecation dynamics and behavior profiles in encopretic children. Pediatrics. 1987;80(5):672-9. [PubMed:3670968]. 
9. Benninga MA, Voskuijl WP, Akkerhuis GW, Taminiau JA, Buller HA. Colonic transit times and behaviour profiles in children with defecation disorders. Arch Dis Child. 2004;89(1):13-6. [PubMed: 14709493].

10. Thompson WG, Longstreth GF, Drossman DA, Heaton KW, Irvine EJ, Muller-Lissner SA. Functional bowel disorders and functional abdominal pain. Gut. 1999;45 Suppl 2:II43-7. doi: 10.1136/gut.45.2008.ii43. [PubMed: 10457044].

11. Wald A, Sigurdsson L. Quality of life in children and adults with constipation. Best Pract Res Clin Gastroenterol. 2011;25(1):19-27. doi: 10.1016/j.bpg.2010.12.004. [PubMed: 21382576].

12. Youssef NN, Langseder AL, Verga BJ, Mones RL, Rosh JR. Chronic childhood constipation is associated with impaired quality of life: a casecontrolled study. J Pediatr Gastroenterol Nutr. 2005;41(1):56-60. doi: 10.1097/01.mpg.0000167500.34236.6a. [PubMed:15990631].

13. Ozokutan BH, Zoroglu S, Ceylan H, Ozkan KU. Psychological evaluation of children with idiopathic constipation and their parents. Pediatr Int. 2005;47(3):311-5. doi: 10.1111/j.1442-200x.2005.02061.x. [PubMed: 15910457].

14. Akbari H, Gilasi HR, Gharlipour Z. Validation of pediatric quality of life questionnaire (pedsql)in kashan city [in Persian]. SciJ Ilam Uni Med Sci. 2014;22(3):10-8.

15. Golding J, Pembrey M, Jones R, Alspac Study Team . ALSPAC-the Avon Longitudinal Study of Parents and Children. I. Study methodology. Paediatr Perinat Epidemiol. 2001;15(1):74-87. doi: 10.1046/j.13653016.2001.00325.x. [PubMed: 11237119].

16. Faleiros FT, Machado NC. Assessment of health-related quality of life in children with functional defecation disorders. J Pediatr (Rio J). 2006;82(6):421-5. doi: 10.2223/JPED.1530. [PubMed: 17003943].
17. Bellman M. Studies on encopresis. Acta Paediatr Scand. 1966:Suppl 170:1+. [PubMed: 5958527].

18. Joinson C, Heron J, Butler U, von Gontard A, Avon Longitudinal Study of P, Children Study T. Psychological differences between children with and without soiling problems. Pediatrics. 2006;117(5):1575-84. doi: 10.1542/peds.2005-1773. [PubMed: 16651311].

19. Sullivan PB, Juszczak E, Bachlet AM, Thomas AG, Lambert B, VernonRoberts A, et al. Impact of gastrostomy tube feeding on the quality of life of carers of children with cerebral palsy. Dev Med Child Neurol. 2004;46(12):796-800. doi: 10.1111/j.1469-8749.2004.tb00443.x. [PubMed: 15581151].

20. Quigley EM, Vandeplassche L, Kerstens R, Ausma J. Clinical trial: the efficacy, impact on quality of life, and safety and tolerability of prucalopride in severe chronic constipation-a 12-week, randomized, double-blind, placebo-controlled study. Aliment Pharmacol Ther. 2009;29(3):315-28. doi: 10.1111/j.1365-2036.2008.03884.x. [PubMed: 19035970].

21. Freud S. On sexuality: Three essays on the theory of sexuality and other works.(first published in 1905). Penguin Freud Library; 1991.

22. Freud S. London: Penguin; 1991. p. 375.On Sexuality.

23. Berzoff J, Flanagan LM, Hertz P, Basham K, Heller NR. Inside out and outside in: Psychodynamic clinical theory and psychopathology in contemporary multicultural contexts. New York: Jason Aronson; 2008. pp. 229-42.

24. Hamilton NG, Sacks LH, Hamilton CA. Object relations theory and pharmacopsychotherapy of anxiety disorders. Am J Psychother. 1994;48(3):380-91. [PubMed: 7992869]. 